\title{
Large Tattoos and Personality: which Women are at Risk?
}

\author{
Stevi Deschler ${ }^{1}$, Lisa Schönberg ${ }^{2}$, Erich Kasten ${ }^{3 *}$ \\ Medical School Hamburg (MSH), University of Applied Sciences, Germany. \\ *Corresponding Author: Erich Kasten, Medical School Hamburg, University of Applied Sciences, Am Kaiserkai 1, \\ D-20457 Hamburg, Germany.
}

\section{Abstract}

Introduction: A selective cross-sectional study of tattooed individuals investigated how personality traits influence the reasons for tattoos.

Methods: Data were based on a survey of 803 tattooed women (aged 16-57 years). All subjects completed the Big Five personality test and a risk-taking test and provided answers to questions about their tattoos.

Results: Extraverts had a greater extent of tattooed skin area than introverts. No correlation was found comparing the willingness to take risks, conscientiousness, agreeableness and extent of the tattooed skin area size. Openness positively correlated with the size of the tattooed skin areas. Neurotic people had a smaller extent of tattooed skin area than emotionally stable participants. Extraversion positively correlated with the tattoo design of individuality. Openness positively correlated with sexual motivations. No correlations were noticed for agreeableness or group affiliations. Neuroticism did not correlate with spiritual and cultural traditions of tattoos. Conscientiousness did not correlate with tattoos as markings of life events. Risk-taking positively correlated with driven-to-the-limits experiences.

Discussion: Individual personality traits have an influence on the motivation for getting tattoos as well as on the size of the area of tattooed skin.

Keywords: Tattoos; personality; risk-taking; tattoo size.

\section{INTRODUCTION}

Today, everyone from rock stars to Hollywood icons and celebrity athletes to ordinary people wears tattoos. ${ }^{1,2}$ Since the 1990s, tattoos have become increasingly popular, creating a veritable new fashion trend. ${ }^{3,4}$ For thousands of years, people all over the world, belonging to different cultures, have been tattooed. In ancient history, tattoos served not only as a status symbol, as jewellery, amulet, tribal affiliation, and declarations of love and of religious beliefs but also as sanctions. 3, 5, 6,7 The ancient Greeks as well as the ancient Romans used tattoos to mark slaves, criminals and/or prostitutes. In World War II, during the Holocaust, prisoners were tattooed with a registration number on their arms as an identification for transport. ${ }^{2,3,5}$

At present, most people get tattooed for personal reasons. ${ }^{8}$ In the last two decades, various studies have shown that tattooed people tend to display certain personality traits, e.g., increased risk-taking behaviour, higher extraversion, higher sensation seeking and an increased need for sex, lower conscientiousness and lower agreeableness than people without tattoos. Likewise, tattooed people tend to feel a higher need to be more unique than non-tattooed people. ${ }^{9-13}$ Copes and Forsyth ${ }^{14}$ observed that tattooed people were more frequently extraverted and constantly seeking external stimulation than non-tattooed individuals. Further studies suggested that having tattoos is associated with risk-taking behaviours as well as the use of illegal substances. ${ }^{15-16}$

Carroll and co-workers ${ }^{9}$ observed significant connections between tattoos, drug use, eating disorders, suicidality, and a high frequency of sexual behaviour. Studies have also confirmed relationships between tattoos and sexuality. Tattooed men and 
women are more likely to have first sexual intercourse at an early age and to have more sexual partners at their age than non-tattooed people. ${ }^{10-11,17}$

Most people get tattooed to enhance their attractiveness. ${ }^{3}$ In addition, tattoos offer people the opportunity to identify with their idols, to belong to a special group or to receive attention from others. Tattoos can even be used for protest or rebellion. In addition to this perspective, tattoos also represent a nonverbal form of communication. Consciously or unconsciously, a tattoo expresses signals about the personality of its owner.

Other studies found that tattooed women were perceived as less attractive, more promiscuous and as heavier drinkers than women without tattoos. ${ }^{18-}$ ${ }^{19}$ These claims aren't linked to the social beauty of women. As a rule, beauty refers to the appearance of body and face. Some people still associate tattoos with male sailors and criminals, so tattooed women still struggle with sexist prejudice today.

Reasons for tattoos are manifold and individual. Several studies have explored the motivational aspects of tattoos as well as for other body modifications. ${ }^{8}$ For example, Millner and Eichold ${ }^{20}$ found that the search for individuality is one of the most important reasons for tattoos and/or piercings.

Dimitropoulos and co-workers ${ }^{21}$ found that the majority of respondents wore tattoos as a reminder of events. A study at the Walter Reed Army Medical Center suggested that military tattoos serve as a sign of proud individualism. ${ }^{22}$ Most people associate tattoos with art and beauty. Tattoos can be a way to commemorate important life events, each tattoo telling a story about parts of an individual's life. ${ }^{3}$

Wohlrab and colleagues ${ }^{8}$ developed ten motivational categories of body modifications: beauty or art and fashion, individuality, personal narration, physical stamina (e.g., enduring pain), group affiliation or engagement, resistance (e.g., protest, rebellion), sexual motivation, addiction, spiritual tradition, and cultural tradition. Beauty and self-enhancement are important reasons for tattooed women, but for men, the reason is more often to be part of a group. ${ }^{23}$ For women with borderline symptoms, the processing of negative life events is an important reason for body modifications. ${ }^{24}$ After sexual abuse, people often stated that they wanted to overcome these negative experiences through piercings or tattoos. Other individuals were characterized by an addiction for body modifications. ${ }^{25}$

Pajor, Broniarczyk-Dyla and Switalska ${ }^{26}$ found that people with body modifications are characterized by a higher sense of self-confidence than people without modifications. Furthermore, in this study, people with body modifications showed fewer social impairments and sleep disorders than the group without modifications.

Based on the results of these studies, the present investigation was performed to examine the influence of personality traits on the motivation to get a tattoo and on the size and kind of the tattoo. The following hypotheses were generated.

The 12 hypotheses of this study assumed that: (H1) Extraverted people have significantly larger areas of tattooed skin than introverted people; (H2) participants with a high conscientiousness score on the personality test have significantly less tattooed skin area than people with a low conscientiousness score; (H3) subjects with a high openness score on the personality test have significantly larger tattooed skin areas compared with participants with low openness values; (H4) people with high anxiety have significantly less tattooed skin area than less anxious participants; (H5) subjects with a high level of agreeableness have significantly less tattooed skin surface than those with a less value; (H6) high risktaking people have significantly larger tattooed areas than those with lower risk-taking tendencies.

(H7) presumes that extraverted subjects provide individuality as a reason for their tattoos significantly more often than introverted subjects; (H8) participants with a high level of conscientiousness more often give the marking of personal life events as a reason for their tattoos than others with a low conscientiousness value; (H9) assumes that people with a high degree of openness give sexual motivations as a reason for being tattooed significantly more often than people with a low level of openness.

The following questions have not been examined in previous investigations. The first hypothesis stated that the participants with a high level of agreeableness offer group affiliation as a reason for being tattooed significantly more often than people with low agreeableness. Next was investigated whether highly 
anxious people give spiritual and cultural traditions as a reason for tattooing significantly more often than the group with low anxiety, and the last hypothesis examines whether people with high risk-taking behaviour offer driven-to-the-limits experiences as a reason for tattooing significantly more often compared with less risk-taking people.

\section{Methods}

A selective cross-sectional study of tattooed people was conducted to investigate the above hypotheses. An online questionnaire was created in German and English languages; it included questions about sociodemographic variables and about the participant's tattoos, as well as two standardized tests to investigate participants' willingness to take risks and their personality traits. To include people without access to a computer, subjects also had the opportunity to receive the questionnaire in a paperpencilversion. The questionnaire (83 items) integrated the Big Five Inventory-10 (BFI-10) by Rammstedt and $\mathrm{John}^{27}$ and a short scale for measuring willingness to take risks (R-1) by Beierlein, Kovaleva, Kemper and Rammstedt. ${ }^{28}$ Further components included a question for collecting sociodemographic information (e.g., gender, age, nationality...), items about the tattoo(s) (e.g., number of palms of the hand needed to cover the tattoos, positions of the tattoos: hands, legs...), reasons for getting tattooed (e.g., underlining your own personality, for medical reasons...) and the choice for this special design (e.g., flowers, stars, animals, names,...). The total processing time was approximately 15 minutes for all items. There is a positive vote from the local ethics committee from 05 May 2017.

\section{RESULTS}

\section{Sample}

A total of 803 tattooed women completed the questionnaire, aged between 16 and 57 years (M
$=29.85, \mathrm{SD}=8.44)$. Of these, $64 \%(\mathrm{n}=613)$ were German citizens, 6\% $(n=56)$ were Swiss, 5\% $(n=48)$ were Austrians, 4.5\% ( $\mathrm{n}=42)$ were Luxembourgish, and $20.5 \%(n=128)$ were citizens of other countries. The size of the tattooed area was estimated using the number of palms of the hand needed to cover the tattoos; the mean was 11.97 palms (SD = 16.85). The minimum of the self-identified tattooed skin area was 0.5 palms of the hand, and the maximum was a total size of 200 palms.

Table 1 offers an overview of the reasons for getting tattoos. The most frequently cited reason for tattoos was to underline one's own personality $(\mathrm{M}=4.16$, $\mathrm{SD}=.98$ ), and the second most often mentioned was the memory of a beloved person or of a beloved pet $(\mathrm{M}=3.68, \mathrm{SD}=1.49)$. Reasons categorized under "others" included, for example, self-protection, branding a slave, property, power, food for thought, passion and fascination with various music styles and sports. Figure 1 provides an overview of the different types of designs for the tattoos. The most frequently mentioned designs were flowers, stars and hearts (61.6\%), animals (53.1\%), citations and statements $(51.7 \%)$, names $(39.7 \%)$ and the date of a specific life event (29.8\%). The most unpopular designs were jail teardrops or dots $1 \%$, closely followed by erotic pictures (2.9\%). Designs categorized as "others" included, for example, passion for one's profession, mandalas, compasses, clocks, geometric signs, pentagrams, trees of life, animal paws, hobbies or interest / passion for music or sports, feathers, infinity symbols, CTG and ECG lines or cancer cells. Figure 2 shows a general overview of the positions of the tattoos. The most preferred body part for tattoos was arms or hands (75.5\%), closely followed by legs / feet (65.1\%), shoulders (55.7\%) and back (53.1\%). The face, at just $2.6 \%$, is the most unpopular body part for tattoos. Areas categorize as "others" included, for example, ears, fingers, toes, lips, buttocks, the groin and the inner surfaces of various body parts.

Table 1. Motivation for tattoos ( $N=803$ ) on a scale 1 ("disagree strongly") to 5 ("agree strongly").

\begin{tabular}{|c|c|c|}
\hline Motivation for tattoos & $M^{1}$ & $S D^{2}$ \\
\hline 1. Underlining your own personality & 4.16 & .98 \\
\hline 2. The tattoo should remind me forever of a loved one or a beloved pet & 3.68 & 1.49 \\
\hline 3. Memories of a particular life situation & 3.61 & 1.45 \\
\hline 4. I regard my skin as a living work of art & 3.47 & 1.34 \\
\hline $\begin{array}{l}\text { 5. Overcoming traumatic experiences/to overcome negative emotional } \\
\text { states or difficult times }\end{array}$ & 2.93 & 1.61 \\
\hline
\end{tabular}


Large Tattoos and Personality: which Women are at Risk?

\begin{tabular}{|l|c|c|}
\hline 6. Increasing attractiveness & 2.73 & 1.28 \\
\hline 7. Marking of a new life stage & 2.70 & 1.55 \\
\hline 8. Underlining femininity & 2.45 & 1.25 \\
\hline 9. I want to show my independence & 2.42 & 1.37 \\
\hline 10. Spontaneously, out of a good mood & 2.12 & 1.36 \\
\hline 11. I was just curious & 2.04 & 1.20 \\
\hline 12. Limiting experiences & 1.95 & 1.29 \\
\hline 13. Religious / spiritual importance & 1.69 & 1.18 \\
\hline 14. To try drastic new things & 1.66 & 1.01 \\
\hline 15. Love and lovesickness & 1.58 & 1.12 \\
\hline 16. For medical reasons & 1.58 & 1.14 \\
\hline 17. Protest, rebellion & 1.57 & 1.00 \\
\hline 18. Underlining masculinity & 1.55 & .95 \\
\hline 19. Belonging to a group & 1.31 & .75 \\
\hline 20. Sexual motives & 1.29 & .77 \\
\hline 21. Because my idols also wear tattoos & 1.26 & .65 \\
\hline 22. Fetishism, exhibitionism, S / M & 1.21 & .63 \\
\hline 23. Youthful folly that I regret today & 1.17 & .53 \\
\hline
\end{tabular}

${ }^{1}$ Mean ${ }^{2}$ Standard Deviation

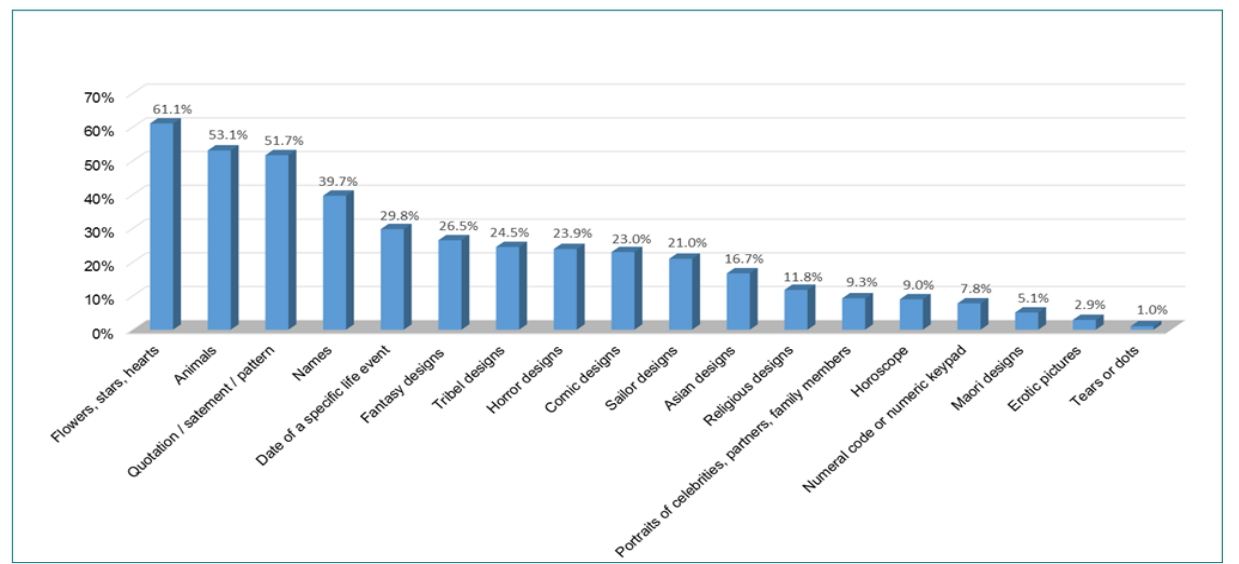

Figure 1. Distribution of tattooed people in terms of the different types of tattoo designs $(N=803)$. The participants could provide multiple responses. Among all participants, 731 had an area of tattooed skin larger than 2 palms of the hand.

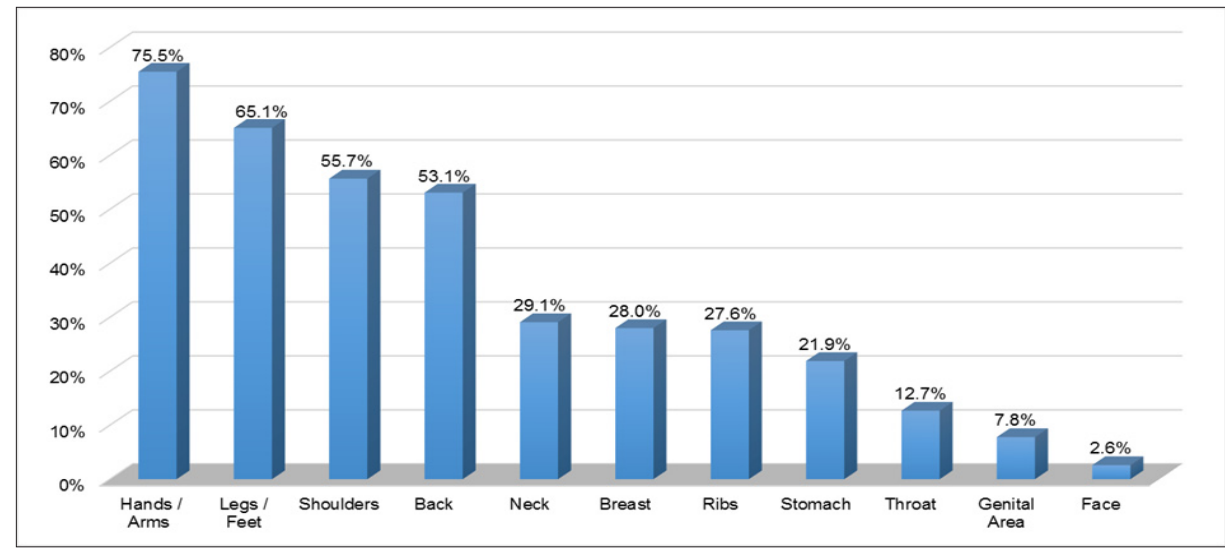

Figure 2. Distribution of tattooed people in terms of tattoo position $(N=803)$. The participants could provide multiple responses. Among all participants, 731 had an area of tattooed skin larger than 2 palms of the hand. 


\section{Detailed Results}

This investigation's main question was to examine which personality traits exert an influence on tattoos; it should also be investigated how personality traits influence the reasons for tattoos. Data were ordinal, so the non-parametric Spearman correlation method was implemented.

For the first hypothesis, a very weak significant positive correlation was observed, $r(803)=.063, p=.038$. The second hypothesis can be confirmed because the correlation calculation, $r(803)=.083, p=.009$, indicates that there is a significantly positive correlation between the two variables. For the third hypothesis, a significant but weak positive correlation was found, $r$ $(803)=.088, p=.006$. The acceptance of the fourth hypothesis was confirmed because the correlation calculation indicates a slight negative correlation, $r$ $(803)=-.079, p=.012$. The fifth hypothesis cannot be confirmed because the correlation calculation shows no significant result, $\mathrm{r}(803)=-.050, \mathrm{p}=.077$. The sixth hypothesis also cannot be confirmed, as no significant relationship was found, $\mathrm{r}(803)=.017$, $\mathrm{p}=.313$. For the seventh hypothesis, a significantly positive correlation between the variables was found, $r(803)=.064, p=.034$. The connections assumed by the eighth hypothesis cannot be confirmed, $\mathrm{r}(803)=$ $-.008, \mathrm{p}=.410$. The acceptance of the ninth hypothesis can be confirmed, as the relationship is positive, but it is very weak, $r(803)=.077, \mathrm{p}=.014$. The tenth hypothesis cannot be confirmed, as the relationship between the two variables is negative, $r(803)=-.053$, $\mathrm{p}=.069$. The eleventh hypothesis cannot be confirmed, $\mathrm{r}(803)=.030, \mathrm{p}=.202$. The twelfth hypothesis cannot be proved, $\mathrm{r}(803)=.057, \mathrm{p}=.053$.

\section{Discussion}

Tattoos are far from serving only as fashionable accessories; they are a kind of nonverbal communication, and individual profound motivations play an essential role when a person looks for a picture, word or sentence for her or his tattoo. The results of this study show interesting connections between personality traits, the size of the tattooed area, and the motivations for tattoos. Six out of 12 hypotheses showed significant results. Compared with other studies, underlining one's personality and memorializing a person, a pet or a life phase were the most important motivations. ${ }^{3,8,29}$ In general, the results reflect that personality traits influence the motivation for tattoos and the extent of the tattooed skin area.

Brooks and colleagues ${ }^{15}$ found in their study that wearing tattoos is associated with risk-taking behaviour and the use of illegal substances. The assumption of a correlation between risk-taking behaviour and extent of the tattooed skin area was not confirmed in our study. Thus, our results do not indicate that an increased willingness to take risks is a precondition for having a larger area of tattooed skin.

Previous studies have shown that tattooed people present higher levels of extraversion and a greater need to feel unique than non-tattooed individuals. ${ }^{13,30}$ Copes and Forsyth ${ }^{14}$ found that most tattooed people sought external stimulation much more frequently than the non-tattooed group. In the present study, extraverted participants had a larger amount of tattooed skin area compared with introverts. One reason for this could be that extraverted people like to be in the middle of society and that they want to feel unique and therefore tend to want more numerous or larger tattoos than introverts. In addition, underlining their individuality plays an essential role for extraverted people. A connection was also found between the personality trait "conscientiousness" and the extent of tattooed skin. People with a high conscientiousness score have less tattooed skin area than people with a low score in conscientiousness. A possible reason for this could be that people with higher consciousness scores feel more dutiful, and may love and respect their bodies how they are. ${ }^{31-32}$

Furthermore, a connection between the personality trait "openness to new experiences" and the extent of tattooed skin was observed. Specifically, this result means that people with a high level of openness had a greater extent of tattooed skin area than people with a lower level. Other authors have found comparable results. ${ }^{31-32}$

The assumption that people with high anxiety scores on the personality test have less extensive tattooed skin area than less anxious people was confirmed in this study. One reason may be that these individuals are more afraid of the pain and anxious because of the possible side effects of tattoos. ${ }^{31-33}$

The hypothesis that extraverts are more likely than introverts to be tattooed to emphasize their personality 
Large Tattoos and Personality: which Women are at Risk?

was confirmed in this study. Extraverts tend to feel more unique than introverts. ${ }^{13,30}$ For extraverts, the underlining of their personality is used to gain more attention from others.

People with a high openness score are more likely to give a sexual motivation as a reason for tattoos than people with a low level of openness. The current literature describes that people with high openness levels more often have new experiences, ideas, and actions. ${ }^{31-32}$ Therefore, it can be supposed that people with a high level of openness also find it easier to have new sexual experiences than people with a low level of openness.

People with high risk-taking behaviour more often give driven-to-limits experiences as a motivation for tattoos than people with low risk-taking behaviour, although that hypothesis cannot be confirmed in this study. Risk-takers love dangerous adventures. To pursue that certain "kick", such people are willing to accept any dangers, inconveniences and/or pain; nonetheless, there is no relationship demonstrated between risk-taking and tattoos. People with low risk behaviour try to avoid danger as much as possible ${ }^{34-}$ ${ }^{35}$, but they are as likely to get tattooed as high risktakers.

A criticism of this study is that the estimation of the tattooed area of the skin can cause slight distortions, since the individual palm was used as a measuring instrument. For future studies, it is advisable to use the formula from the medicine for palm determination for the estimation of the tattooed skin area.

\section{ConCLUSION}

In principle, this study shows that the individual characteristics of personality traits have a possible influence on individuals' motivation for tattoos and on the extent of the tattooed skin area size.

\section{REFERENCES}

[1] Bickerstaff, L. (2005). Tattoos: Fad, Fashion, or Folly? Odyssey, 14 (5), 34-36.

[2] Hofmeister, D., Borkenhagen, A., \& Brähler, E. (2013). Körpermodifikation. Von Stigma zum Status [Body modification. From stigma to status]. Psychosozial: Schwerpunktthema: Homo plasticusPsychosoziale Aspekte schönheitschirugischen Enhancements [Psychosocial: Main topic: Homo plasticus - Psychosocial aspects of beauty-surgery enhancements], pp. 77-90.
[3] Selekman,J.(2003). A new era of body decoration: what are kids doing to their bodies? Pediatric nursing, 29 (1), 77-79. doi: PMID: 12630514

[4] Zestcott, CA., Tompkins, TL., Kozak Williams, M., Livesay, K., \& Chan, KL. (2017). What do you think about ink? An examination of implicit and explicit attitudes toward tattooed individuals. The Journal of Social Psychology, 158 (1), 7-22. do i:10.1080/00224545.2017.1297286

[5] Dankemeyer, I. (2010). Personenbeschreibungen. Zur Kulturgeschichte und Aktualität der Tätowierung [Personal descriptions. On cultural history and timeliness of the tattoo]. Retrieved from https://jungle.world/artikel/2010/37/ personenbeschreibungen

[6] Lineberry, C. (2007). Tattoos: The ancient and mysterious history. Retrieved from Smithsonian: https://www.smithsonianmag.com/history/ tattoos-144038580/

[7] Ward, C. (1984). Thaipusam in Malaysia: A Psycho-Anthropological Analysis of Ritual Trance, Ceremonial Possession and Self-Mortification Practices. Ethos - Journal of the society for psychological anthropology, 12 (4), 307-334. doi:10.1525/eth.1984.12.4.02a00020

[8] Wohlrab, S., Stahl, J., \& Kappeler, P. (2007). Modifying the body: motivations for getting tattooed and pierced. Elsevier, 4 (1), 87-95. doi:10.1016/j.bodyim.2006.12.001

[9] Carroll, ST., Riffenburgh, RH., Roberts, TA., \& Myhre, E. B. (2002). Tattoos and Body Piercings as Indicators of Adolescent Risk-Taking Behaviors. Pediatrics, 109 (6), 1021-1027. doi: 10.1542/ peds.109.6.1021

[10] Guéguen, N. (2012a). Tattoos, piercings, and sexual activity. Social Behavior and Personality: An international journal, 40, 1543-1547. doi: https://doi.org/10.2224/sbp.2012.40.9.1543

[11] Heywood, W., Patrick, K., Smith, A., Simpson, J. M., Pitts, M., Richters, J., \& Shelley, J. (2012). Who gets tattoos? Demographic and behavioral correlates of ever being tattooed in a representative sample of men and women. Elsevier, 22 (1), 51-56. doi:10.1016/j.annepidem.2011.10.005 
Large Tattoos and Personality: which Women are at Risk?

[12] Swami, V. (2012). Written on the body? Individual differences between British adults who do and do not obtain a first tattoo. Scandinavian Journal of Psychology, 53, 407-412. doi:10.1111/j.14679450.2012.00960.x

[13] Tate, J., \& Shelton, B. L. (2008). Personality correlates of tattooing and body piercing in a college sample: The kids are alright. Personality and Individual Differences, 45 (4), 281-285. doi:10.1016/j.paid.2008.04.011

[14] Copes, JH., \& Forsyth, CJ. (1993). The Tattoo: A Social Psychological Explanation. International Review of Modern Sociology, 23 (2), 83-89.

[15] Brooks, TL., Woods, ER., Knight, JR., \& Shrier, LA. (2003). Body modification and substance use in adolescents: is there a link? Journal of Adolescent Health, 32 (1), 44-49. doi: https://doi. org/10.1016/S1054-139X(02)00446-9

[16] Ball, I., Farnill, D., \& Wangeman, J. (1984). Sex and age differences in sensation seeking: Some national comparisons. British Journal of Psychology, 75 (2), 257-265. doi:10.1111/j.20448295.1984.tb01897.x

[17] Nowosielski, K., Sipiński, A., Kuczerawy, I., Kozłowska-Rup, D., \& Skrzypulec-Plinta, V. (2012). Tattoos, Piercing, and Sexual Behaviors in Young Adults. Journal of Sexual Medicine, 9 (9), 23072314. doi:10.1111/j.1743-6109.2012.02791.x

[18] Guéguen, N. (2012b). Tattoos, Piercings, and Alcohol Consumption. Alcoholism Clinical and Experimental Research, 36 (7), 1253-1256. doi: 10.1111/j.1530-0277.2011.01711.x

[19] Swami, V., \& Furnham, A. (2007). Unattractive, promiscuous and heavy drinkers: perceptions of women with tattoos. PubMed, 4 (4), 343-352. doi: 10.1016/j.bodyim.2007.06.005

[20] Millner, VS., \& Eichold, BH 2nd. (2001). Body Piercing and Tattooing Perspectives. Clinical Nursing Research, 10 (4), 424-441. doi:https:// doi.org/10.1177/C10N4R7

[21] Dimitropoulos, V., Brown, CW., Ressa, NA., \& Newman, M. (2016). Reasons behind the ink. Europe PMC, 98 (5), 320-322.

[22] Lande, R., Bahroo, B., \& Soumoff, A. (2013). United States military service members and their tattoos: a descriptive study. Mil Med, 178 (8), 921925. doi:10.7205/MILMED-D-13-00131

[23] Horne, J., Knox, D., Zusman, J, \& Zusman, M. (2007). Tattoos and piercings: Attitudes, behaviors, and interpretations of college students. College Student Journal, 41 (4), 1011-1020.

[24] Höhner, G., Teismann, T., \& Willutzki, U. (2013). [Tattoos and Piercings: Motives for Body Modification in Women Suffering from Borderline Symptomatology]. Psychotherapie Psychosomatik Medizinische Psychologie, 64 (2), 63-69. doi:10.1055/s-0033-1347255

[25] Stirn, A., Oddo, S., Peregrinova, L., Philipp, S., \& Hinz, A. (2011). Motivations for body piercings and tattoos - the role of sexual abuse and the frequency of body modifications. Psychiatry Research, 190 (2-3), 359-363. doi:10.1016/j. psychres.2011.06.001

[26] Pajor, A., Broniarczyk-Dyla, G., \& Switalska, J. (2015). Satisfaction with life, self-esteem and evaluation of mental health in people with tattoos or piercings. Psychiatria polska, 49 (3), 559-573. doi:10.12740/PP/27266

[27] Rammstedt, B., \& John, O. P. (2007). Measuring Personality in One Minute or Less: A 10-Item Short Version of the Big Five Inventory in English and German. Journal of Research in Personality, 41 (1), 203-212. doi: 10.1016/j.jrp.2006.02.001

[28] Beierlein, C., Kovaleva, A., Kemper, C. J., \& Rammstedt, B. (2014). Kurzskala zur Erfassung der Risikobereitschaft (R-1) [Short scale for recording the willingness to takes risks (R-1)]. Zusammenstellung sozialwissenschaftlicher Items und Skalen, 1-18. doi:doi:10.6102/zis236

[29] Carmen, R. A., Guitar, A., \& Dillon, H. M. (2012). Ultimate Answers to Proximate Questions: The Evolutionary Motivations Behind Tattoos and Body Piercings in Popular Culture. Review of General Psychology, 16 (2), 134-143. doi:10.1037/ a0027908

[30] Swami, V., Pietschnig, J., Bertl, B., Nader, I., Stieger, S., \& Voracek, M. (2012). Personality differences between tattooed and non-tattooed individuals. Psychological Reports: Mental \& Physical Health, 111 (1), 97-106. doi:10.2466/09.07.21. PRO.111.4.97-106 
Large Tattoos and Personality: which Women are at Risk?

[31] Maltby, J., Day, L., \& Macaskill, A. (2011). Differentielle Psychologie, Persönlichkeit und Intelligenz [Differential psychology, personality and intelligence] (2nd ed.). München: Pearson Studium.

[32] Rammsayer, T. (2016). Ausgewählte eigenschafts theoretische Konzepte [Selected property theory concepts]. In T. Rammsayer \& H. Weber (Eds.), Differentielle Psychologie.Persönlichkeitstheorien [Differential Psychology- Personality Theories] (pp. 222-238). Göttingen: Hogrefe.
[33] Asendorf, J. (2011). Persönlichkeitspsychologie für Bachelor [Personality Psychology for Bachelor] (2nd ed.). Heidelberg: Springer.

[34] Raithel, J. (2011). Jugendliches Risikoverhalten. Eine Einführung [Adolescent risk behavior. An introduction] (2nd ed.). Wiesbaden: VS Verlag.

[35] Zuckerman, M. (2007). Sensation Seeking and Risky Behavior. Washington, DC: American Psychological Association.

Citation: Stevi Deschler, Lisa Schönberg, Erich Kasten. Large Tattoos and Personality: which Women are at Risk?. Archives of Dermatology and Skin Care. 2020; 3(2): 09-16.

Copyright: (C) 2020 Stevi Deschler, Lisa Schönberg, Erich Kasten. This is an open access article distributed under the Creative Commons Attribution License, which permits unrestricted use, distribution, and reproduction in any medium, provided the original work is properly cited. 